\title{
Study on Ultrafine Particles Used in Drilling Fluids
}

\author{
$X C \mathrm{CaO}^{1, *}, C Y \mathrm{Zhou}^{2}, Y Y \mathrm{Li}^{3}, W \mathrm{Zong}^{4}, J \mathrm{Wang}^{5}$ and $M \mathrm{Chen}^{6}$ \\ ${ }^{1}$ School of Petroleum Engineering, Northeast Petroleum University,Daqing, HLJ 163318, China \\ ${ }^{2}$ School of Information Technology and Electrical Engineering,University of Queensland, Brisbane, QLD 4072, AU \\ ${ }^{3}$ Liaohe Oilfield Information Engineering Co. LTD., Panjin, LN 124010, China \\ ${ }^{4}$ Research Institute of drilling and production technology, Panjin, LN 124010, China \\ ${ }^{5}$ Production Technology Institute of Daqing Oilfiled Co. Ltd., Heilongjiang Provincial Key Laboratory of Oil and Gas Reservoir \\ Stimulation, Daqing, HLJ 163453, China \\ ${ }^{6}$ Engineering and Technical Departmengt of No.2 Oil Plant of Daqing Oilfield, Daqing, HLJ 163453, China
}

\begin{abstract}
In this paper, several ultrafine particles were prepared and characterized, then the performance of drilling fluids were evaluated after ultrafine particles were added in water base drilling fluids. The viscosity property of drilling fluids were increased, however, filtration reduction could not be strictly controlled. All filtration volume was difficult to control just like common ultrafine calcium carbonate unless some polymers could be used. Titanium dioxide and zinc dioxide could be used as substitutes of calcium carbonate in drilling fluids.
\end{abstract}

\section{Introduction}

In order to provide various essential functions of oil/gas drilling fluids, a few kinds of nano materials are applied in typical formula of drilling fluids. Oil and gas drilling fluids or muds are circulating fluids used in rotary drilling to perform various functions required in the oil and gas drilling operation. In order to provide various functions, many kinds of materials (such as water, oil, clay, etc.) and agents (such as shale inhibitors, viscosity reducers, flocculants, filtration reducers, etc.) are applied in typical formula of drilling fluids.

Nowadays, researchers have been paying more and more attention to health, safety and environmental management (HSE), meanwhile oil reservoir protection has been highlighting. The most widely used technology is membrane formation technique[1-3], in which the most useful functional matter called temporary bridging agent should be applied. These agents are actually nano and micro particles. Clay, generally speaking, the most basic material in drilling fluids, is a kind of nano particles when it is dispersed in alkaline water. Bentonite, this specifically used clay, should be hydrated, swelled and dispersed in water to be smaller than microdimension to provide higher yield [2,3]. Therefore, drilling fluids, especially water base drilling fluids, are usually considered as colloid system when we analyze its performance of hydration and electricity [4,5].

\section{Nano and micro materials in drilling fluids}

*Corresponding author: caoxiaochun_nepu@163.com

\subsection{Category of nano materials}

Nano materials, also known as ultrafine particles, is composed of nano particles, generally refers to the size of particles between $1 \mathrm{~nm}$ and $100 \mathrm{~nm}$ (sometimes 1000 $\mathrm{nm})$. Nano materials is usually divided into following three categories according to their geometric shape:

- Nano particles, or zero dimensional nano materials because they are among nanometer scale in three-dimension, eg. ultrafine calcium carbonate used as temporary bridging agents.

- Nano fibers, or one-dimensional nano materials referring to the fiber which has one dimension among nanometer scale, eg. salt-resisting clay used in saturated saltwater drilling fluids.

- Nano thin film,or two-dimensional nano materials which are thin films or membranes because their thickness is among nanometer scale, for instance, bentonite used as the basic materials in water base drilling fluids.

\subsection{Special characteristic of nano materials}

Nano materials have following special characteristics:

- $\quad$ Surface effects, which have very large specific surface area and high surface activity.

- Small size effect, with the particle size change, under certain conditions will cause the change of particle properties. It is important for us to prepare stable water base drilling fluids.

- Quantum size effect, namely because of individual nanoparticles contain atoms rarely, will 
produce and usually contain infinite atomic bulk material completely different phenomenon.

\subsection{Formatting author affiliations}

We surveyed the relative articles published in Journals through internet with Chinese searching tool of MedaLink. Every year hundreds and thousands of articles on drilling fluids have been published, some ultrafine particles except clay are mentioned[1]. According to MedaLink, we compared the amount of articles in Chinese with that in English (seen in Figure 1). Obviously, researchers on drilling fluids are paying more attention to nano particles in recent years. However, the amount of Chinese articles somehow decreased.

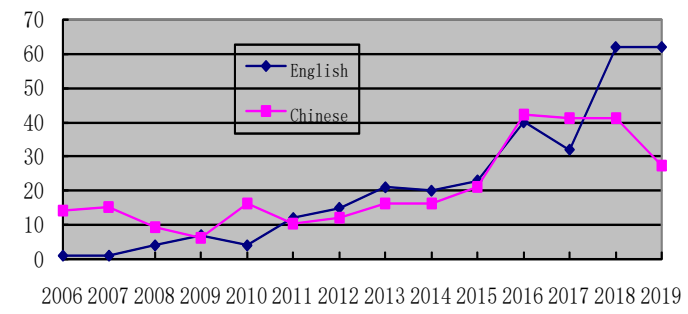

Fig. 1. Comparison articles on "drilling fluids" and "nano" published in China and abroad.

\section{Preparation and evaluation of ultrafine particles for drilling fluids}

\subsection{Preparation of ultrafine particles}

\subsection{1 $\mathrm{Mg}(\mathrm{OH})_{2}$ ultrafine particles}

Add $40 \mathrm{~mL} 1.2 \mathrm{~mol} / \mathrm{L} \mathrm{MgCl}_{2}$ aqueous solution into 160 $\mathrm{mL} \mathrm{NaOH}$ aqueous solution until the value of $\mathrm{pH}$ was 8.5. Then add SAS/OP-10 with $3 \%$ amount of $\mathrm{Mg}(\mathrm{OH})_{2}$. After stirring for 3 hours, filtrate and flush the production with deionized distilled water. Then, dry for $3 \mathrm{~h}$ at $120{ }^{\circ} \mathrm{C}$ and grind to obtain $\mathrm{Mg}(\mathrm{OH})_{2}$ powder.

\subsection{2 $\mathrm{Al}_{2} \mathrm{O}_{3}$ ultrafine particles}

Mix equal amount of aluminium sulfate and ammonium carbonate aqueous solution at the condition of $55^{\circ} \mathrm{C}$ with PEG 600 as the dispersing agent and stir (1400 rpm) for more than $1 \mathrm{~h}$. Then wash, filtrate, dry and grind to get the precursor. Calcine above $1000{ }^{\circ} \mathrm{C}$ for more than $2 \mathrm{~h}$ to obtain the objective product.

\subsubsection{ZnO ultrafine particles.}

Add $10 \%$ aqueous ammonia into $\mathrm{ZnCl}_{2}$ aqueous solution with $\mathrm{pH}$ value of $9 \sim 10$. Filtrate and dry the product at $280^{\circ} \mathrm{C}$ for $1 \mathrm{~h}$, then grind the product to obtain $\mathrm{ZnO}$ powder.

\subsection{4 $\mathrm{TiO}_{2}$ ultrafine particles.}

Soak cotton fiber with mixture of tetrabutyl titanate and anhydrous alcohol at the ratio of 1:30, then calcine at $500{ }^{\circ} \mathrm{C}$ for $2 \mathrm{~h}$.

\subsection{Evaluation of performance of drilling fluids with nano materials}

\subsubsection{Preparation of base mud.}

Mix 5\% bentonite (Wt./Vol.) and $0.25 \%$ sodium carbonate (Wt./Vol.) with water in specific mud cup, stirring with high speed for $20 \mathrm{~min}$, then stewing at room temperature for $24 \mathrm{~h}$.

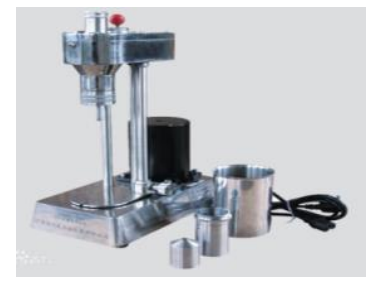

Fig. 2. Viscometer.

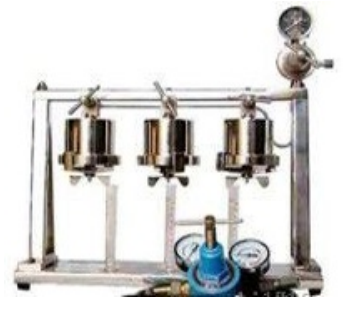

Fig. 3. Filtration press.

\subsubsection{Measurement of rheological property of base mud with and without adding ultrafine particles.}

The rheological property is usually analyzed using a 6speed viscometer (seen in Figure 2). All measurements are carried out according to Chinese national standards (GB).

Testing mechanism of water base drilling fluids is mainly as follows:

- The viscometer has 6 rotational speeds including $3 \mathrm{rpm}, 6 \mathrm{rpm}, 100 \mathrm{rpm}, 200 \mathrm{rpm}, 300 \mathrm{rpm}$ and $600 \mathrm{rpm}\left(\theta_{3}, \theta_{6}, \theta_{100}, \theta_{200}, \theta_{300}\right.$ and $\left.\theta_{600}\right)$.

- Using a set of six speeds reading, a rheological curve of rpm versus dial reading of the tested drilling fluids can be built up.

- $\quad$ Then calculate all reheological property such as apparent viscosity $(A V)$, plastic viscosity $(P V)$, yield point $(Y P)$, and gel strength $(G)$, and then evaluate the viscosity property of a specific drilling fluid.

\subsubsection{Measurement of filtration property of base mud with and without adding ultrafine particles.}

API filtration can be measured using API filtration press (seen in Figure 3). All measurements are carried out according to Chinese national standards (GB).

Testing mechanism of water base drilling fluids is mainly as follows:

- API filtration can be measured under a pressure of $690 \pm 6.9 \mathrm{kPa}$ using a proper filter paper, Whatman NO. 50 or equivalent.

- The test period begins at the time of pressure operation. At the end of $30 \mathrm{~min}$, read the volume of filtrate.

- Record the volume of filtrate in cubic centimeters as the API filtrate $(F L)$. Save the filtrate for appropriate chemical testing if necessary. 
- Measure the thickness $(B)$ of the filter cake in millimeters.

\section{Calculation of rheological parameters}

Several rheological models are used in drilling fluids, among which Bingham Model is the most popular. According to Bingham Model, important parameters can be estimated as follows:

$$
\begin{gathered}
A V=0.5 \theta_{600}, \mathrm{mPa} \cdot \mathrm{s} \\
P V=\theta_{600}-\theta_{300}, \mathrm{mPa} \cdot \mathrm{s} \\
Y P=0.511\left(\theta_{300}-P V\right), \mathrm{Pa} \\
G_{1^{\prime}} \text { or } G_{10^{\prime}}=0.511 \theta_{3}, \mathrm{~Pa}
\end{gathered}
$$

\section{Results and analysis}

\subsection{Grain size analysis}

After fine particles were prepared, we carried out analysis of grain size. According to Figure 4, we prepared three kinds of ultrafine particles: flake as (a), spherical as (b) and (c), and fiber as (d) and (e). As for (f), ultrafine calcium carbonate, a commonly used temporary bridging agent in drilling fluids, especially when drilling in oil/gas reservoir.

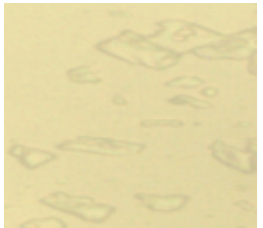

(a) $\mathrm{Mg}(\mathrm{OH})_{2}(\times 40)$ $(\times 40)$

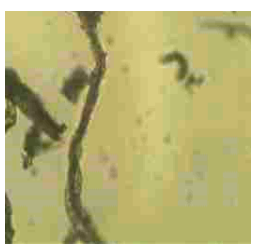

(d) $\mathrm{TiO}_{2} \quad(\times 40)$

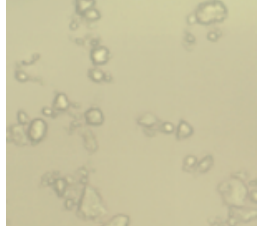

(b) $\mathrm{Al}_{2} \mathrm{O}_{3}(\times 40)$

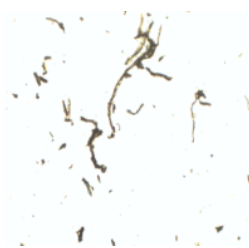

(e) $\mathrm{TiO}_{2}(\times 10)$ $(\times 40)$

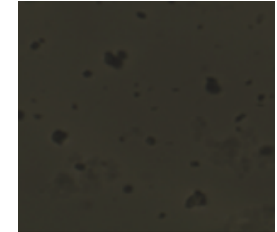

(c) $\mathrm{ZnO}$

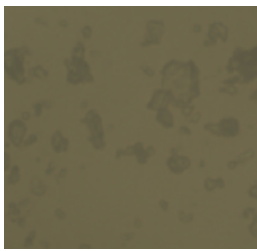

(f) $\mathrm{CaCO}_{3}$
Fig. 4. Grain size analysis of ultrafine particles using optical microscope.

\subsection{Evaluation of performance of drilling fluids}

According to Table 1, the shear thixotropy of drilling fluids $\left(\mathrm{G}_{1}, / \mathrm{G}_{10}\right.$, were enhanced, especially for $\mathrm{Mg}(\mathrm{OH})_{2}$ ultrafine particles, which might be explained by its different flake shape. All the values of viscosity and yield points were increased slightly, the mechanism of which could be interpreted by more friction due to increase of solid contents. Another special particle is
$\mathrm{Al}_{2} \mathrm{O}_{3}$ with comparatively less gel strength especially compared to magnesium hydroxide, which could be due to similar composition to the bentonite. Nevertheless, further research is highly recommended.

Obviously, filtrate volume could not be strictly controlled because all the filtration volume was larger than that of base mud and all filtrate cakes were thicker. Filtrate reducers can reduce filtration volumes and improve the quality of filter cakes in water base muds. It would be better if some polymers as filtrate reducers were used $[1,3]$.

Table 1. Measured rheological filtration parameters of base mud and $1 \%$ ultrafine particles

\begin{tabular}{ccccccc}
\hline & $A V$ & $P V$ & $Y P$ & $G_{1^{\prime}} / G_{10^{\prime}}$ & $\begin{array}{c}F L \\
(\mathrm{ml})\end{array}$ & $\begin{array}{c}B \\
(\mathrm{~mm})\end{array}$ \\
\hline Base mud & 15 & 8 & 7 & $6.5 / 8.0$ & 17.0 & 1.0 \\
$\mathbf{M g}(\mathbf{O H})_{2}$ & 17 & 8 & 9 & $18.0 / 19.0$ & 19.6 & 1.5 \\
$\mathbf{A l}_{2} \mathbf{O}_{3}$ & 17 & 8 & 9 & $8.0 / 9.0$ & 23.0 & 1.2 \\
$\mathbf{Z n O}$ & 16 & 8 & 8 & $7.0 / 20.0$ & 19.0 & 1.5 \\
$\mathbf{T i O}_{2}$ & 18 & 10 & 8 & $7.0 / 17.5$ & 18.5 & 1.5 \\
$\mathbf{C a C O}_{3}$ & 18 & 10 & 8 & $7.0 / 17.5$ & 18.4 & 1.3 \\
\hline
\end{tabular}

Some prepared particles had similar functions to common ultrafine calcium carbonate except magnesium hydroxide and aluminium oxide. Therefore, when calcium carbonate is not capable to increase the weight of drilling fluid, titanium dioxide and zinc dioxide could be the alternative due to their larger densities than that of calcium carbonate.

\section{Conclusion}

The conclusion is summarized as follows:

- $\quad$ Four kinds of ultrafine particles were prepared and evaluated.

- $\quad$ Both viscosity and shear thixotropy of drilling fluids were enhanced, especially for $\operatorname{Mg}(\mathrm{OH})_{2}$ ultrafine particles.

- All filtration volume was difficult to control just like common ultrafine calcium carbonate.

- Titanium dioxide and zinc dioxide could be used as substitutes of calcium carbonate in drilling fluids.

\section{Acknowledgments}

Authors wish to acknowledge assistance of all students and encouragement from all colleagues of School of Petroleum Engineering at Northeast Petroleum University.

\section{References}

1. Sun J S, Liu J P, Yan L L, et al. J 2016 J. Drilling Fluid \& Completion Fluid vol 5 (Chinese) p 1

2. Li M C, Ren S X, Zhang X Q, Dong L L, Lei T Z, Lee S Y and Wu Q L.ACS J 2018 J. Appl. Nano Mater. vol 1 p 7039-7051 
3. Wu Y P, Tian Y P, Luo P Y and Lin Y H. J 2019 J. Drilling Fluid \& Completion Fluid vol 4 (Chinese) p 407

4. Ho C Y, Yusup S, Soon C V. J 2014 J. Adv. Chem. Eng vol 4 p 115

5. Li D, Hong B, Fang W, Guo Y, Lin R. J 2010 J . Ind. Eng. Chem. Res. vol 49 p 1697-1702 